\title{
Stylomastoid Foramen Osteoma: Unique Challenges for Appropriate Management
}

\author{
Aisha Larem, Sally Sheta, Abdulsalam Al-Qahtani, Hassan Haidar* \\ Department of Otolaryngology, Hamad Medical Corporation, Doha, Qatar \\ Email: $\underline{\text { Hahmad2@hamad.qa }}$
}

Received 2 June 2015; accepted 3 July 2015; published 6 July 2015

Copyright (C) 2015 by authors and Scientific Research Publishing Inc.

This work is licensed under the Creative Commons Attribution International License (CC BY).

http://creativecommons.org/licenses/by/4.0/

(c) (i) Open Access

\begin{abstract}
Osteoma of the temporal bone is a rare and slow-growing benign tumor. It is reported to affect almost all portions of the temporal bone. However, osteoma involving the stylomastoid foramen has never been reported in the literature. We report a case of an osteoma extending from the stylomastoid foramen and occluding the external auditory canal in a young female. Although the osteoma has very close relationship with the facial nerve, it was removed because of the severity of its associated symptomatology; the osteoma was completely removed without any postoperative complications. This report is of interest as it highlights the challenges in the management of osteomas in such localization.
\end{abstract}

\section{Keywords}

Osteoma, Temporal Bone, Stylomastoid Foramen, Facial Nerve

\section{Introduction}

Osteomas are benign neoplasms formed of mature bone and arising almost exclusively from bone made in membrane, e.g. the skull. In the head and neck region, they are usually found in the front oethmoid area [1] [2]. Temporal bone osteomas are a rare entity [3], and when this occurs, they are most commonly seen in the external auditory canal (canalicular osteomas). Extra canalicular temporal osteomas, such as mastoid osteomas are even more infrequent [4]. Osteomas are usually asymptomatic [5]; in symptomatic cases, typically due to cosmetic deformity, treatment of the osteoma is surgical, but in symptomatic cases involving noble structures, the management can be challenging.

In this report, we present a case of a 43-year-old female patient with a large osteoma extending from the stylomastoid foramen (SMF) and filling the EAC and we discuss the challenges regarding the treatment of this lesion.

${ }^{*}$ Corresponding author.

How to cite this paper: Larem, A., Sheta, S., Al-Qahtani, A. and Haidar, H. (2015) Stylomastoid Foramen Osteoma: Unique Challenges for Appropriate Management. International Journal of Otolaryngology and Head \& Neck Surgery, 4, $277-281$. 


\section{Case Report}

A 43-year-old female, previously healthy, was referred to our center due to a long-standing history of right recurrent otitis externa that become very frequent and invalidating. She reports also progressive right sided hearing loss. There were no accompanying symptoms of vertigo or tinnitus in her medical history.

Otolaryngologic examination revealed a hard, immobile, mildly tender mass with erythematous overlying skin filling the right EAC, occluding view to the tympanic membrane. The left ear was normal. Facial nerve examination was intact bilaterally. No other masses were palpated in the head and neck region. On audiogram, right conductive hearing loss was revealed.

A temporal bone CT scan indicated a well demarcated, dense, sclerotic mass of approximately $2.3 \times 2 \mathrm{~cm}$ of the right mastoid process filling the EAC and extending inferiorly to the SMF, the mass was very near but not involving the mastoid segment of the fallopian canal. The middle and inner ear were normal. The radiologic appearance was suggestive of osteoma (Figure 1).

Because of the severity of her symptoms, especially severe and refractory otitis externa, the patient was asking for definitive treatment. An extensive discussion was done with her on the risk of facial nerve injury because of the critical localization of the lesion. The patient accepted the risk and signed a medical consent of high risk of postoperative facial palsy.

The resection of tumor was performed using posterior transmastoid approach (Figure 2). A facial monitor was used due to the close proximity of the facial nerve. After a cortical mastoidectomy, the mastoid segment of the facial nerve was identified and followed down till the SMF. The osteoma was identified in the anteroinferior part of the mastoid process about $1 \mathrm{~mm}$ lateral to the fallopian canal; the posterior and inferior walls of the EAC were replaced by the tumor which was filling the lateral part of the EAC and extending inferiorly on the vaginal process till the base of styloid process. A gradual drilling around the tumor was performed, taking care of the proximity of the facial nerve, till the mass was complete excised en bloc. Reconstruction of the EAC was done using tragal cartilage and fascia that was covered by the remaining skin. The canal was dressed with gauze with antibiotic and corticoid unguent for 2 weeks (Figure 2).

The postoperative period was smooth, facial nerve function was intact. Three weeks later, the EAC dressing was removed; the canal was patent and wide and completely epithelized. Histopathology result confirmed the diagnosis of osteoma (Figure 3).

In subsequent follow-up in the 18 ensuing months, patient remained asymptomatic and relieved from the cosmetic, inflammatory and auditory symptoms.

\section{Discussion}

Temporal bone osteomas are very rare benign osteogenic tumors. When they occur, they are seen most commonly in the EAC. Here they arise from the site lateral to the isthmus of the EAC, with its base being located at
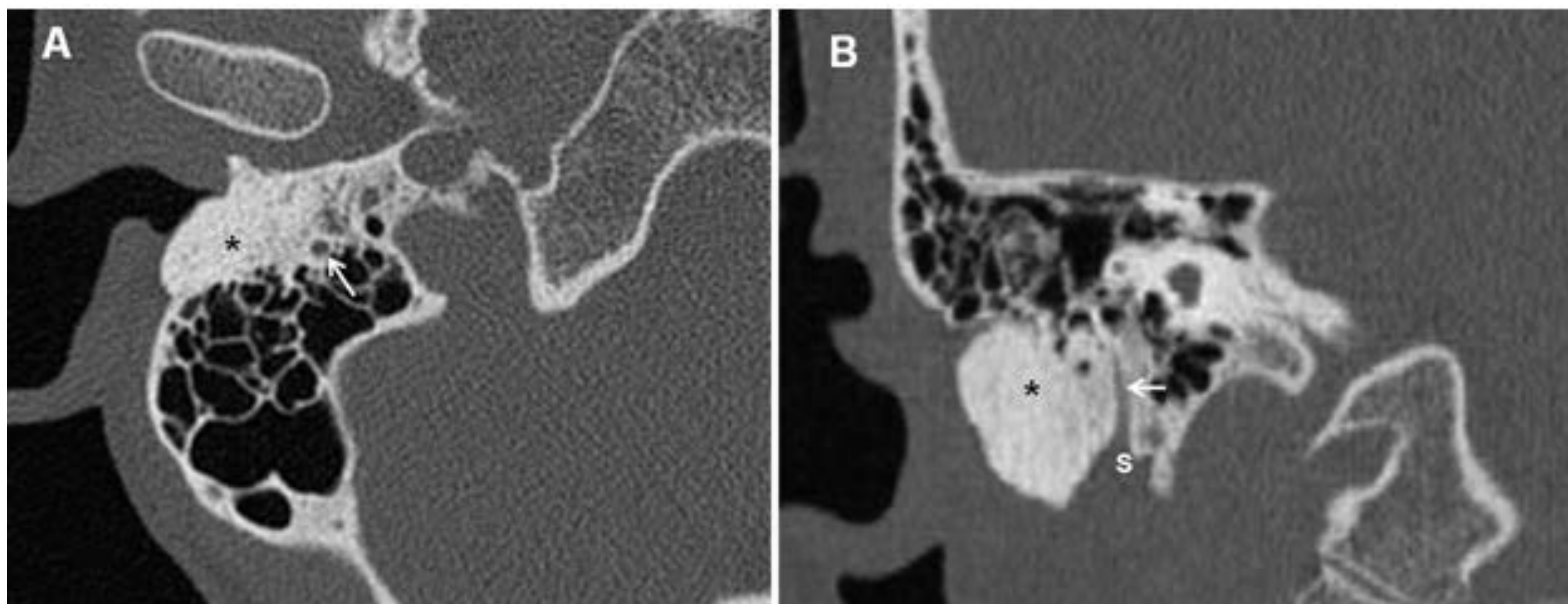

Figure 1. Right Temporal bone CT scan, Axial cut A and saggital cut B showing a hyperdense bony mass $(*)$ occluding the ear canal extending posteriorly into the mastoid in close relationship with the facial nerve(white arrow) and inferiorly to the stylomastoid foramen (S). 

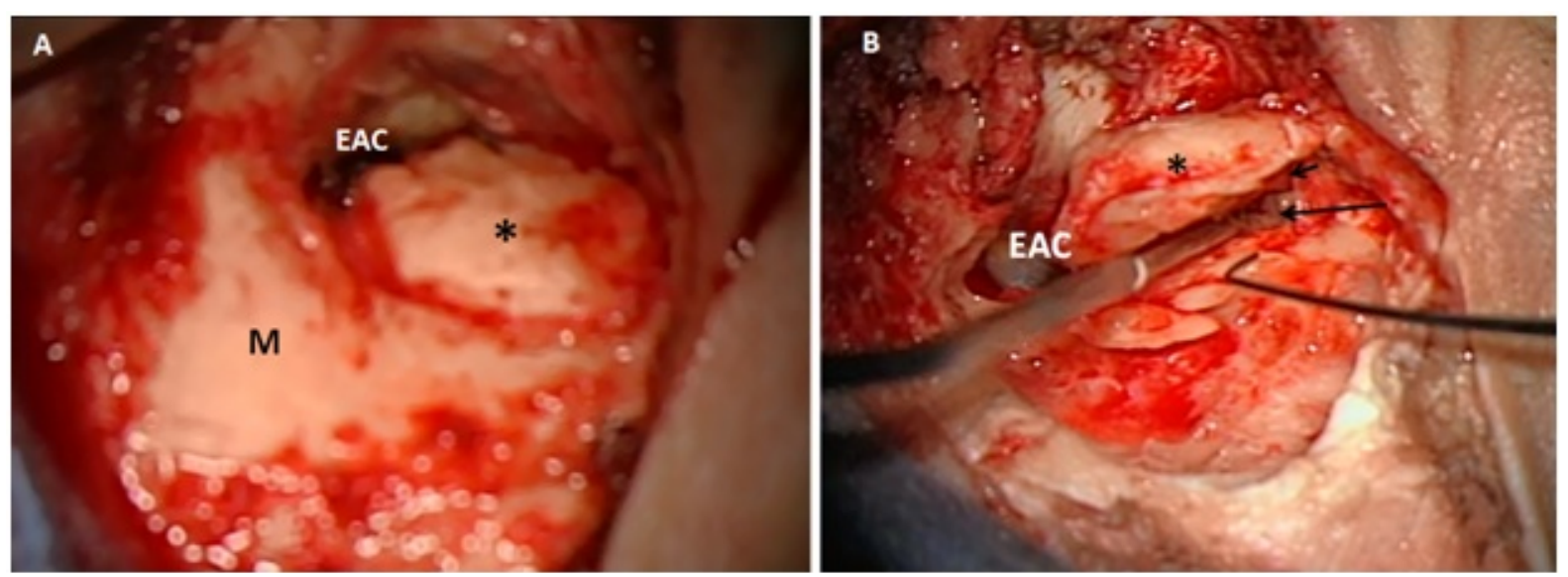

Figure 2. Operative view of posterior approach of right ear. A: a big osteoma (*) filling the ear canal (EAC) and extending to the mastoid cortex (M) and extending inferiorly. B: after cortical mastoidectomy, the mastoid facial nerve is identified till its emergence from the stylomastoid foramen (long arrow); osteoma (*);styloid process (short arrow).

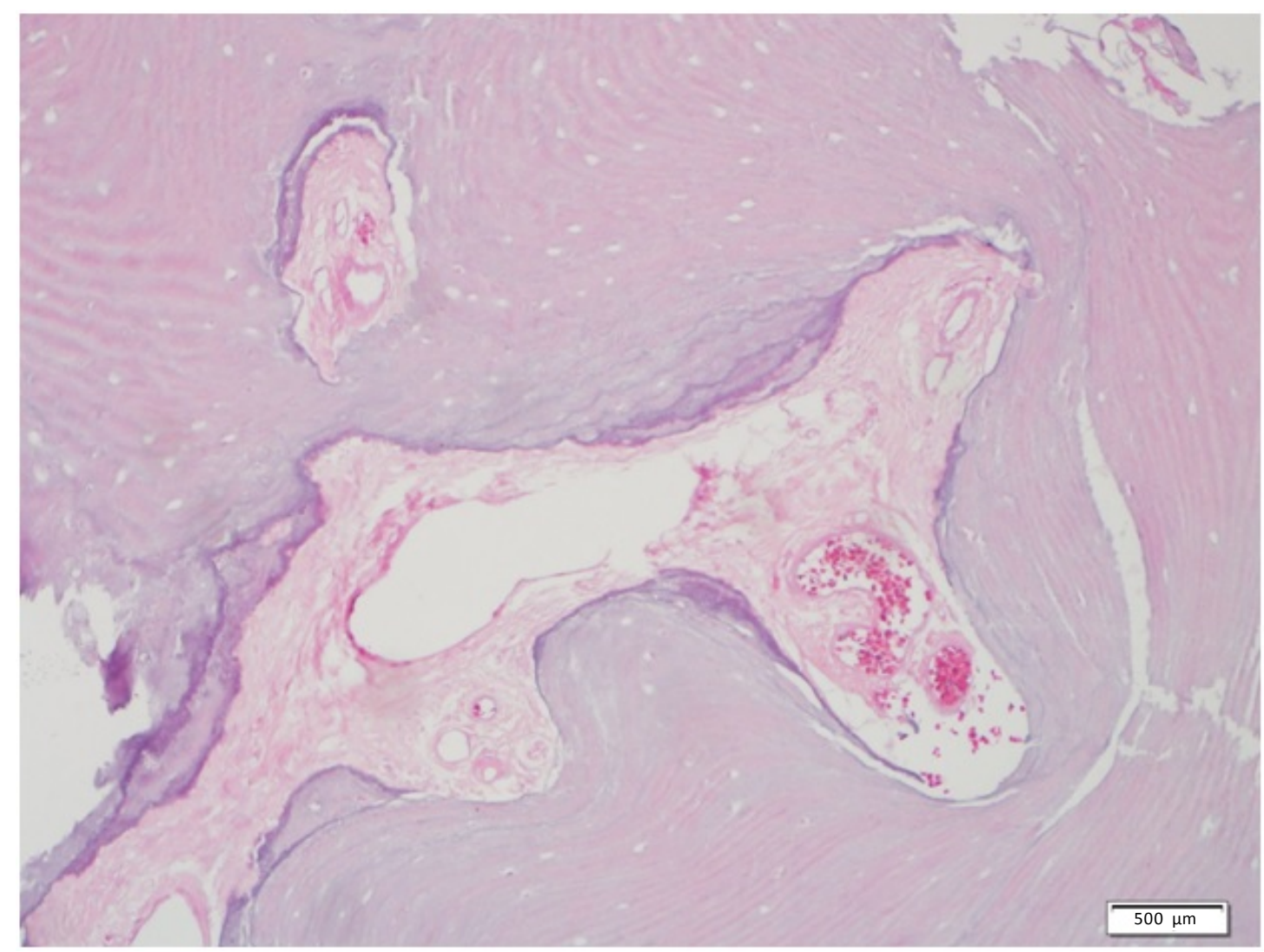

Figure 3. Histopathological assessment of the bony tumor excised. Sections show dense, mature, predominantly lamellar bone. Interosseous space is mostly composed of scant fibrovascular tissue.

the tympanosquamous or tympanomastoid suture lines adjacent to the bony-cartilaginous junction in most cases. An osteoma originates from the preosseous connective tissue in these suture lines as they have a thicker subcutaneous layer and a richer blood supply than the other parts of the bony canal. Canalicular osteomas are usually localized to the external auditory canal; however, canalicular osteomas extending to the stylomastoid foramen have never been reported in literature.

Although an osteoma of the EAC grows slowly and remains stable for many years, symptoms such as con- 
ductive hearing impairment or recurrent infection can arise if the osteoma grows to a point of canal obstruction. Hearing loss occurs due to retention of epithelial residues and wax, rather than mechanical obstruction of the conductive passage by the tumor. A secondary cholesteatoma can ensue [6].

Diagnosis is usually confirmed by CT scanwhere osteomas appear as a well circumscribed mass with soft tissue density, egg-shell like density or bone density.

When it comes to histopathological assessment, osteomas are formed of mature bone. Three histological patterns are identified. The compact/ ivoryosteoma consists of dense bone lacking Haversian systems. The cancellous/spongioform osteoma often resembles "normal" bone with central trabeculae containing bone marrow. The mixed osteoma shows both the compact and cancellous variety.

The main treatment for an EAC osteoma is a surgical excision. The size and location of the osteoma as well as the severity of symptoms determine the treatment. Patients with a small osteoma and little or no symptoms may be treated in a conservative manner. Surgical excision is recommended if a growing osteoma results in occlusion of the canal and the patient complains of recurrent infection and/or conductive hearing impairment. When the osteoma is located at the lateral portion of the isthmus and is a peduncular type, it can be easily removed by an osteotome or drilling through the transmeatal approach. When an osteoma is located medial to the isthmus, is huge, or has a broad base, it is safe to remove it through the postauricular approach [7]-[11]. However, for cases with a large posterior wall defect the canal wall down mastoidectomy or canal wall up mastoidectomy with posterior wall reconstruction can be used [12] [13].

It is reported that in cases of osteomas extending into the fallopian canal, complete excision is not indicated since there is risk of damage to the facial nerve [14]. However, it is reported also that partial surgical excision by drilling on the tumor tissue may result in recurrence of tumor that may grow medially to encroach on vital structures making potential future revision excision challenging [14]. The definitive treatment of osteoma remains of complete resection by drilling around the osteoma and avoiding damage to vital structures [15].

In this case, the patient had a huge osteoma occluding almost the entire EAC and an extensive extension posteriorly and inferiorly in a close relationship with the mastoid segment of the fallopian canal till the SMF. Therefore, a canal wall up mastoidectomy and identification of the mastoid segment of the facial nerve from the second genu till the SMF was done first before resection of the osteoma; the inferior and posterior wall of the auditory canal was reconstructed using cartilage.

Prognostically, there are very rare situations where osteomas have recurred post excision, all of which were in long bones and there are no reported cases of recurrence in the head and neck region.

\section{Conclusion}

In conclusion, osteomas are rare osteogenic tumors that frequently pose no issues for the patient. Symptomatic osteomas in accessible regions can be successfully removed with few complications. Where these tumours involve key structures, as in our case was the facial nerve, surgical management should be planned to complete excise the tumor to avoid recurrence whilst preserving the chief structures.

\section{Disclosure of Interest}

There is no conflict of interest to disclose.

\section{Informed Consent}

Written informed consent was obtained from the patient who participated in this study.

\section{References}

[1] Probst, L.E., Shankar, L. and Fox, R. (1991) Osteoma of the Mastoid Bone. The Journal of Otolaryngology, 20, 228230.

[2] Burton, D.M. and Gonzalez, C. (1991) Mastoid Osteomas. Ear, Nose \& Throat Journal, 70, 161-162.

[3] Unal, O.F., Tosun, F., Yetişer, S. and Dündar, A. (2000) Osteoma of the Middle Ear. International Journal of Pediatric Otorhinolaryngology, 52, 193-195. http://dx.doi.org/10.1016/S0165-5876(00)00286-X

[4] Das, A.K. and Kashyap, R.C. (2005) Osteoma of the Mastoid Bone-A Case Report. Medical Journal Armed Forces India, 61, 86-87. 
[5] Güngör, A., Cincik, H., Poyrazoglu, E., Saglam, O. and Candan, H. (2004) Mastoid Osteomas: Report of Two Cases. Otology \& Neurotology, 25, 95-97. http://dx.doi.org/10.1097/00129492-200403000-00002

[6] Fenton, J.E., Turner, J. and Fagan, P.A. (1996) A Histopathologic Review of Temporal Bone Exostoses and Osteomata. The Laryngoscope, 106, 624-628. http://dx.doi.org/10.1097/00005537-199605000-00020

[7] Graham, M.D. (1979) Osteomas and Exostoses of the External Auditory Canal. A Clinical, Histopathologic and Scanning Electron Microscopic Study. Annals of Otology, Rhinology \& Laryngology, 88, 566-572. http://dx.doi.org/10.1177/000348947908800422

[8] Tran, L.P., Grundfast, K.M. and Selesnick, S.H. (1996) Benign Lesions of the External Auditory Canal. Otolaryngologic Clinics of North America, 29, 807-825.

[9] Fisher, E.W. and McManus, T.C. (1994) Surgery for External Auditory Canal Exostoses and Osteomata. The Journal of Laryngology \& Otology, 108, 106-110. http://dx.doi.org/10.1017/S0022215100126027

[10] Sheehy, J.L. (1982) Diffuse Exostoses and Osteomata of the External Auditory Canal: A Report of 100 Operations. Otolaryngology Head and Neck Surgery, 90, 337-342.

[11] Yamamoto, E., Iwanaga, M. and Sato, K. (1986) Osteoma with Cholesteatoma in the External Auditory Canal. Practica Oto-Rhino-Laryngologica, 79, 575-578. http://dx.doi.org/10.5631/jibirin.79.575

[12] Orita, Y., Nishizaki, K., Fukushima, K., Akagi, H., Ogawa, T., Masuda, Y., Fukazawa, M. and Mori, Y. (1998) Osteoma with Cholesteatoma in the External Auditory Canal. International Journal of Pediatric Otorhinolaryngology, 43, 289-293. http://dx.doi.org/10.1016/S0165-5876(98)00022-6

[13] Vrabec, J.T. and Chaljub, G. (2000) External Canal Cholesteatoma. The American Journal of Otology, 21, $608-614$.

[14] Mustafa, A. (2012) Osteoma of Mastoid Process Obstructing External Auditory Canal: A Case Report. Health, 4, 222224. http://dx.doi.org/10.4236/health.2012.44034

[15] Viswanatha, B. (2011) Characteristics of Osteoma of the Temporal Bone in Young Adolescents. Ear, Nose \& Throat Journal, 90, 72-79. 